DOI: 10.1515/LPTS-2015-0015

\title{
NUMERICAL 2D AND 3D SIMULATIONS OF A SPHERICAL FABRY-PÉROT RESONATOR FOR APPLICATION AS A REFERENCE CAVITY FOR LASER FREQUENCY STABILISATION
}

\author{
E. Nitiss ${ }^{1 *}$, K. Bluss ${ }^{2}$, J. Alnis ${ }^{3}$ \\ ${ }^{1}$ University of Latvia, Institute of Solid State Physics \\ 8 Kengaraga Str., Riga, LV-1083, LATVIA \\ edgarsn@cfi.lu.lv \\ ${ }^{2}$ Optek Ltd. \\ 64 Rigas Av., Adazi, Adazi district, LV-2164, LATVIA
${ }^{3}$ University of Latvia, Institute of Atomic Physics and Spectroscopy
4 Skunu Str., Riga, LV-1586, LATVIA

\begin{abstract}
We report on the results of a numerical study of deformations of a spherical Fabry-Pérot cavity that can be used for laser frequency stabilisation. It is demonstrated that for a precise simulation of the cavity deformations a 3D model has to be used instead of a simpler 2D model, which employs simulation on the symmetry plane of the cavity. To lower the sensitivity to environmental perturbations, it is suggested to use a material with a low density and a high Young's modulus. We also show that the mechanical resonance frequencies of the cavity are mainly determined by the size of the cavity.
\end{abstract}

Keywords: Fabry-Pérot cavity, laser frequency stabilisation, numerical simulations.

\section{INTRODUCTION}

Recently an extensive effort has been devoted towards the development of a low-noise optical frequency standard with a potential to be utilised in various applications in sensing [1], [2], fundamental experiments in physics [3], optical clocks [4] and others [5]. Diverse optical designs have been suggested for the development of low intensity and frequency noise sources [6], [7]. In the development of ultranarrow linewidth sources, laser diodes locked to high finesse Fabry-Pérot (FP) cavities via the Pound-Drever-Hall (PDH) technique [8] prevail. The basic idea of such setup is to maintain the laser frequency within the resonance linewidth of the external cavity using a feedback loop. In the last decades, various FP resonator shapes and stabilisation setups have been suggested, implemented experimentally and simulated numerically [9]-[16]. For the experiments in laboratory conditions, most of the setups, in terms of frequency noise, have reached the thermal limit, which is usually dominated by the resonator mirror coating [17]. The latter suggests that none of the 
designs is far more superior to others if used in the laboratory environment. Thus, a proper choice of the setup should be based on the intended application and conditions. A new concept is to create an ultra-narrow linewidth laser source for application in the field environment, where the mechanical noise is significant [18], [19]. In such a case, a spherical FP cavity could be one of the best options to be used as the optical reference. The spherical FP cavity possesses a "squeeze insensitive angle" at which the deformations of the cavity do not couple to the optical axis [14].

Cleary, due to the costs of the cavity material, before the implementation of such spherical FP resonator-based setup, extensive modelling should be performed in order to calculate the zero fixing angle, sensitivity to external acceleration as well as mechanical resonance frequencies. All of these parameters depend on the FP resonator material constants and cavity shape [13], [20], [21]. In this regard, we present the results of both 2D and 3D numerical simulations of a spherical FP cavity, which demonstrate the dependence of the FP cavity fixing angle, acceleration sensitivity and mechanical resonance frequencies on the FP cavity material constants and cavity size.

\section{METHODS AND MODELS}

In the present research, deformations of a spherical FP cavity are simulated. The simulations are performed using Comsol Multiphysics with the Structural Mechanics module, which employs finite element calculations for finding the deformation of the input geometry based on initial and boundary conditions as well as on surrounding fields, e.g., the gravitational field. The Structural Mechanics module can also calculate the resonance frequencies of the object, which was also exploited.

The input geometry, applied forces and fields are illustrated in Fig. 1A and Fig. $1 \mathrm{~B}$ for $2 \mathrm{D}$ and $3 \mathrm{D}$ simulations, respectively. In case of $2 \mathrm{D}$ simulations, the cavity is defined only in the ZX plane, which is the symmetry plane of the spherical cavity. In case of 3D simulations, the spherical cavity is defined in XYZ coordinates. In both cases, the cavity is fixed at the bottom fixing point but squeezed by the top fixing point with the total force $\mathrm{F}_{-\mathrm{z}}$ equal to $10 \mathrm{~N}$. The gravitational field components have been provided in the directions of $\mathrm{X}, \mathrm{Y}$ and $-\mathrm{Z}$ and are $g_{x}, g_{y}$ and $\mathrm{g}_{-\mathrm{z}}$, respectively, for the $3 \mathrm{D}$ case. Our preliminary calculations have shown that such geometrical orientation is the least sensitive to the gravitational acceleration in the $\mathrm{Y}$ and $-\mathrm{Z}$ direction. The deformation calculations have been performed for cavities with mirror separations $L=50 ; 100 ; 150 \mathrm{~mm}(2 \mathrm{D})$ and $L=50 ; 75 ; 100 ; 125 ; 150 \mathrm{~mm}$ (3D). It is well established that the mirror separation is one of the parameters that determines the $\mathrm{Q}$ factor of the cavity - the longer the cavity, the higher the $\mathrm{Q}$ factor. High Q factors are desired for ultra-narrow linewidth laser stabilisation, because more energy can be stored in a cavity [22]. As evident from Fig. 1, $\theta$ in the models is the angle between the line perpendicular to the optical axis of the cavity and the squeezing axis. It will be further referred to as the squeezing angle. It is justifiable to expect that there is such a squeeze insensitive angle $\theta_{o}$ at which the deformations of the cavity do not affect the mirror separation length $L$. This is due to the fact that at $\theta_{o}$ the vertical and horizontal deformations induced by squeeze force $\mathrm{F}_{-\mathrm{z}}$ on the optical axis of the cavity cancel each other out. The squeeze insensitive angle $\theta_{o}$ can 
be found by calculating the mirror separation change $\Delta L$ as a function of the angle $\theta$. At $\theta_{o}$ the mirror separation change $\Delta L$ is equal to zero and, thus, the cavity is least sensitive to mechanical noise.

As shown later in this paper, the material constants determine $\theta_{o}$, acceleration sensitivity $\Delta L / L$ and the resonance frequencies of the spherical FP cavity. The calculation series will include variation of material constants, which will be changed around the material constants of the Corning Ultra Low Expansion (ULE) glass [14]: Young's modulus E=67.6 GPa, Poisson ratio $p=0.17$ and density $\rho=2210 \mathrm{~kg} / \mathrm{m}^{3}$. Furthermore, the effects of the size on the characteristic parameters of the FP resonator will be demonstrated.

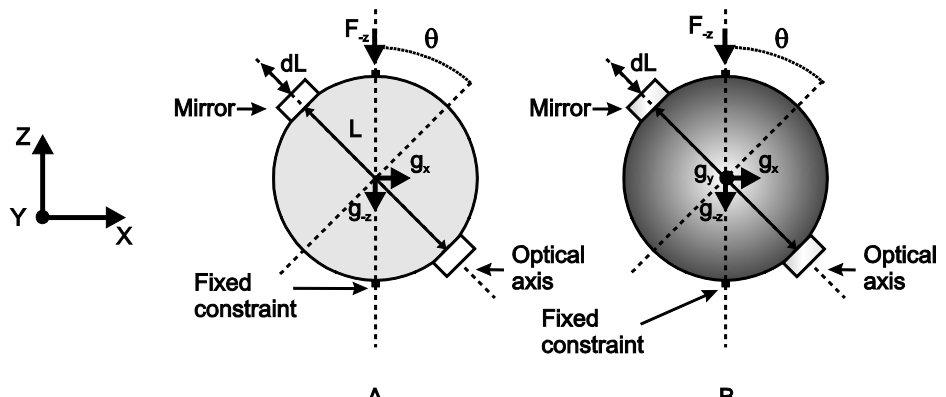

A.

B.

Fig. 1. A. A spherical FP cavity for 2D simulations defined only in ZX plane and assumed to be infinite in the $\mathrm{Y}$ direction. B. A spherical FP cavity for 3D simulations defined in $\mathrm{XYZ}$ coordinates. The $g_{x}, g_{y}$ and $\mathrm{g}_{-\mathrm{z}}$ stand for the components of the gravitational field in the $\mathrm{X}, \mathrm{Y}$ and $-\mathrm{Z}$ directions, respectively. The squeezing force $\mathrm{F}_{-\mathrm{z}}$ is applied from the top. The bottom fixing point is fixed. The squeezing angle $\theta$ is the angle between the line perpendicular to the optical axis of the cavity and the squeezing axis in the $-\mathrm{Z}$ direction.

\section{COMPARISON OF 2D AND 3D SIMULATIONS}

From the perspective of calculation resources, it is evident that using symmetries and performing $2 \mathrm{D}$ simulations are preferable to the $3 \mathrm{D}$ calculations, since the $3 \mathrm{D}$ simulations usually require solving equation systems with more degrees of freedom. Thus, the interest was whether the time-consuming 3D simulations could be substituted by much simpler 2D simulations. We performed numerical deformation calculations for the $2 \mathrm{D}$ and $3 \mathrm{D}$ cases. The material parameters of the spherical cavities with mirror separation $L=50 \mathrm{~mm}$ were set to be those of the Corning ULE glass. The cavity was subjected to a constant squeezing force $\mathrm{F}_{-\mathrm{z}}=10 \mathrm{~N}$ as well as to a constant gravitational body load of $\mathrm{g}_{-\mathrm{z}}=10 \mathrm{~m}^{2} / \mathrm{s}$. For both models, the calculated acceleration sensitivity $\Delta L / L$ as a function of the squeezing angle $\theta$ around the squeeze insensitive angle $\theta_{o}$ is demonstrated in Fig. 2. Within the given $\theta$ range, the data points could be perfectly fitted with the second order polynomials - with the coefficients of determination taking the values of 1 .

As evident from Fig. 2, the squeeze insensitive angles $\theta_{o}$ obtained from 2D and 3D simulations differ significantly even though slopes of the approximation functions are quite similar. The squeeze insensitive angles $\theta_{o}$ were calculated for cavities with mirror separations $L=50 ; 100 ; 150 \mathrm{~mm}(2 \mathrm{D}$ and $3 \mathrm{D})$ and $L=75 ; 125$; (3D only), with a constant squeezing force $\mathrm{F}_{-z}$ of $10 \mathrm{~N}$ as well as a constant gravitational body load $g_{-z}$ of $10 \mathrm{~m}^{2} / \mathrm{s}$ (Fig. 3). It is important to note that for the $3 \mathrm{D}$ model 
with $L=50 \mathrm{~mm}$, the calculated $\theta_{o}$ is very close to the result obtained by Leibrandt and co-workers [14]. From the simulation results two conclusions can be drawn. Firstly, the squeeze insensitive angle $\theta_{o}$ is higher for larger cavities; however, the difference is very small. The squeeze insensitive angles $\theta_{o}$ for $50 \mathrm{~mm}$ and $150 \mathrm{~mm}$ cavities differ by only $0.13^{\circ}$. The difference may be due to increasing contributions of the gravitational field, which is higher for bigger cavities. Secondly, the 2D simulations constantly yield the squeeze insensitive angle $\theta_{o}$ that is by approximately $4.7^{\circ}$ higher than that of 3D modelled cavities. Such a difference could be attributed to the fact that the 3D cavity has finite length and mass in the $\mathrm{Y}$ axis direction which, if deformed by the gravitational field, may influence the deformations in the ZY plane. The obtained results suggest that a $2 \mathrm{D}$ model that implements the symmetry of the spherical cavity should not be used to predict the properties of a spherical FP cavity. Instead, a 3D model has to be employed.

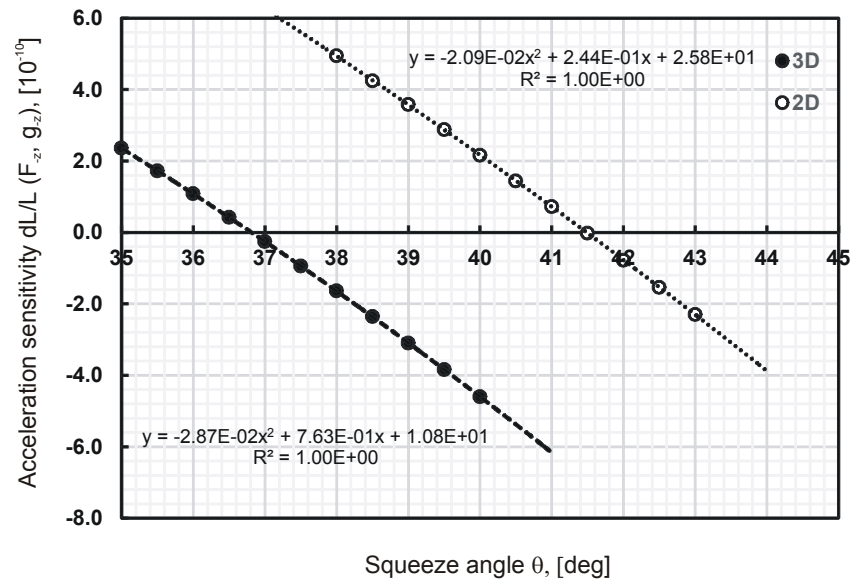

Fig. 2. The calculated acceleration sensitivity $\Delta L / L$ as a function of the squeezing angle $\theta$ for $2 \mathrm{D}$ and 3D models. The material parameters are set as those of the Corning ULE glass: Young's modulus $\mathrm{E}=67.6 \mathrm{GPa}$, Poisson ratio $\mathrm{p}=0.17$ and density $\rho=2210 \mathrm{~kg} / \mathrm{m}^{3}$. The calculation was performed for a spherical cavity with $\mathrm{L}=50 \mathrm{~mm}$. The second order polynomial fit is applied for the data points.

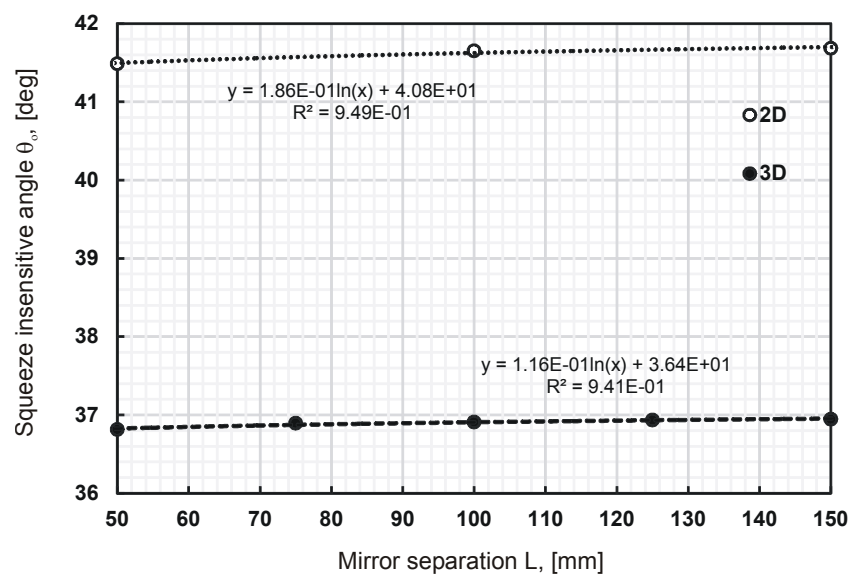

Fig. 3. The calculated squeeze insensitive angles $\theta_{o}$ for cavities with mirror separations $L=50 ; 100$; $150 \mathrm{~mm}$ (2D model) and $L=50 ; 75 ; 100 ; 125 ; 150 \mathrm{~mm}$ (3D model). The material constants were set to be as follows: $\mathrm{E}=67.6 \mathrm{GPa}$, Poisson ratio $p=0.17$, density $\rho=2210 \mathrm{~kg} / \mathrm{m}^{3}$. The boundary conditions include a constant squeezing force $\mathrm{F}_{-\mathrm{z}}=10 \mathrm{~N}$ and a constant gravitational body load of $\mathrm{g}_{-\mathrm{z}}=10 \mathrm{~m}^{2} / \mathrm{s}$. 


\section{THE DEFORMATION AND FIXING ANGLE STUDIES}

Acceleration sensitivity $\Delta L / L$ is one of the crucial parameters of a FP cavity. It determines the amplitude of deformations and, thus, the frequency noise of the stabilised light source through the relation

$$
\frac{\Delta L}{L}=\frac{\Delta f}{f},
$$

where $f$ is the frequency of the laser and $\Delta f$ - the corresponding frequency variation. The acceleration sensitivity $\Delta L / L$ dependence on the external acceleration was calculated as follows. The squeeze insensitive angle $\theta_{o}$ was calculated for each cavity with defined mirror separation and material constants. Then the cavity was fixed at the squeeze insensitive angle $\theta_{o}$ and the time invariant body loads $g_{x}, g_{-y}$ and $g_{-z}$ (in the $\mathrm{X},-\mathrm{Y}$ and $-\mathrm{Z}$ directions, respectively) were applied. During each simulation at various $g_{x}, g_{-y}$ and $g_{-z}, \Delta L / L$ was estimated and normalised to the gravitational acceleration of $g=10 \mathrm{~m} / \mathrm{s}^{2}$.

An important observation from the first $3 \mathrm{D}$ cavity simulation was that the acceleration sensitivity $\Delta L / L$ was the most sensitive to the acceleration in the $\mathrm{X}$ direction (Table 1 ). For a cavity with $L=50 \mathrm{~mm}, \mathrm{E}=67.6 \mathrm{GPa}$, Poisson ratio $p=0.17$, density $\rho=2210 \mathrm{~kg} / \mathrm{m}^{3}$ deformed by $g_{x}, g_{-y}$ and $g_{-z}$, the acceleration sensitivity $\Delta L / L$ in the $\mathrm{X}$ direction was demonstrated to be several orders higher than in the $\mathrm{Y}$ and $\mathrm{Z}$ directions. The reason why the cavity has low sensitivity to the $\mathrm{Z}$ direction acceleration could be that at $\theta_{o}$ the $g_{-z}$ acceleration couples to the vertical squeeze force. In other words, the vertical acceleration $\mathrm{g}_{-\mathrm{z}}$ deforms the sphere almost as if only the vertical squeezing force were applied. And, since by the definition at $\theta_{o} \Delta L / L$ is very small, it is expected that $\Delta L / L$ is low for $g_{-z}$ acceleration. The same simulation demonstrated that $\Delta L / L$ is also very low if the $\mathrm{Y}$ directed acceleration is present. The numerical simulations state that the deformation of the cavity in the Y direction has a small influence on the cavity length L.

Table 1

The Calculated Acceleration Sensitivity $\Delta L / L$ for a Cavity with $L=\mathbf{5 0} \mathbf{~ m m}$,

$\mathrm{E}=$ 67.6 GPa, Poisson Ratio $p=0.17$, Density $\rho=2210 \mathrm{~kg} / \mathrm{m}^{3}$ Deformed by $g_{x}, g_{-y}$ and $g_{-z}$

\begin{tabular}{cc}
\hline Applied acceleration direction & Acceleration sensitivity $\Delta L / L,(1 / \mathrm{g})$ \\
\hline $\mathrm{X}\left(\mathrm{g}_{\mathrm{x}}\right)$ & $2.21 \cdot 10^{-9}$ \\
$-\mathrm{Y}\left(\mathrm{g}_{-\mathrm{y}}\right)$ & $2.03 \cdot 10^{-12}$ \\
$-\mathrm{Z}\left(\mathrm{g}_{-\mathrm{z}}\right)$ & $2.60 \cdot 10^{-11}$ \\
\hline
\end{tabular}

Since the sensitivity in the $\mathrm{X}$ direction was elucidated to be several orders higher than in the $\mathrm{Y}$ and $\mathrm{Z}$ directions, only the horizontal acceleration $g_{x}$ was further used to investigate the acceleration sensitivity $\Delta L / L$ dependence on the FP cavity material constants and its size. As noted previously, the main material constants of the cavity material are the Young's modulus E, the Poisson ratio $\mathrm{p}$ and the density $\rho$. These constants can vary across a wide range depending on the chosen supplier and material. Currently, the materials that could be used for laser frequency stabilisation application are the Corning ULE glass [14], Schott Zerodur glass [23], silica glass [24] and monocrystalline silicon [25], [26]. The basic mechanical parameters and zero expansion temperature, if inherit, are displayed in Table 2. 
Material Constants as well as Zero Expansion Temperature for Materials Most Frequently Utilised in the Development of a FP Cavity

\begin{tabular}{|l|c|c|c|c|}
\hline \multicolumn{1}{|c|}{ Parameter/Material } & $\begin{array}{c}\text { Corning ULE } \\
\text { glass }^{\mathrm{a}}\end{array}$ & $\begin{array}{c}\text { Schott Zerodur } \\
\text { glass }^{\mathrm{b}}\end{array}$ & $\begin{array}{c}\text { Fused silica } \\
\text { glass }^{\mathrm{c}}\end{array}$ & $\begin{array}{c}\text { Monocrystalline } \\
\text { silicon }^{\mathrm{d}}\end{array}$ \\
\hline Young's modulus E [GPa] & 67.6 & 90.3 & 73.1 & $130-187^{\mathrm{e}}$ \\
Poisson ratio $\mathrm{p}$ & 0.17 & 0.24 & 0.17 & $0.20-0.278^{\mathrm{e}}$ \\
Density $\rho\left[\mathrm{kg} / \mathrm{m}^{3}\right]$ & 2210 & 2530 & 2203 & 2327 \\
Zero expansion temperature & $\sim 18^{\circ} \mathrm{C}$ & $\sim 30^{\circ} \mathrm{C}-\sim 130^{\circ} \mathrm{C}$ & - & - \\
\hline
\end{tabular}

${ }^{\mathrm{a}}$ From [14], ${ }^{\mathrm{b}}$ from [23], ${ }^{\mathrm{c}}$ from [27], ${ }^{\mathrm{d}}$ from [28], ${ }^{\mathrm{e}}$ cut-plane-dependent.

As a reference and calculation starting point, we used the Corning ULE glass FP cavity with $E=67.6 \mathrm{GPa}$, Poisson ratio $\mathrm{p}=0.17$ and density $\rho=2210 \mathrm{~kg} / \mathrm{m}^{3}$. Firstly, we estimated the influence of Young's modulus on the squeeze insensitive angle $\theta_{o}$ value and the acceleration sensitivity $\Delta L / L$ of resonator, whose $L=50 \mathrm{~mm}$. The simulations are presented in Fig. 4.

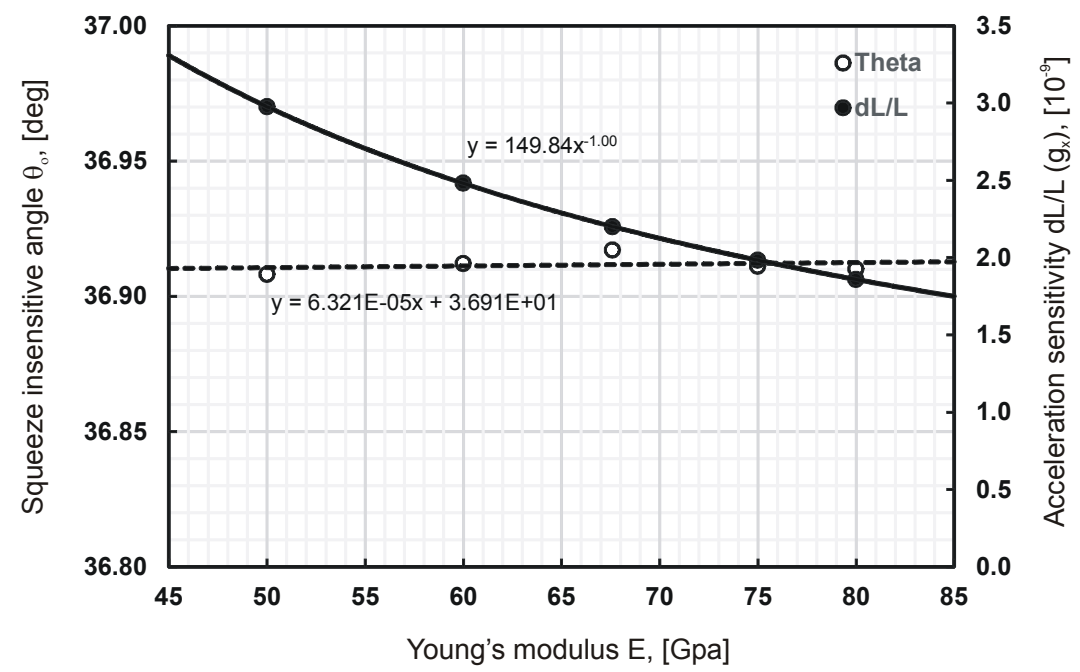

Fig. 4. The calculated squeeze insensitive angles $\theta_{o}$ and acceleration sensitivity $\Delta L / L$ at the corresponding $\theta_{\mathrm{o}}$ of $50 \mathrm{~mm}$ FP cavity as a function of Young's modulus E in GPa. The Poisson ratio and density were set to be $p=0.17$ and $\rho=2210 \mathrm{~kg} / \mathrm{m}^{3}$, respectively. The boundary conditions include a constant squeezing force $\mathrm{F}_{-\mathrm{z}}$ of $10 \mathrm{~N}$ as well as gravitational body load.

Evidently from Fig. 4, the Young's modulus has no effect on the $\theta_{o}$ values. At the same time, the Young's modulus has a significant impact on the acceleration sensitivity $\Delta L / L$. The numerical calculations show that the stiffer the resonator, the lower the $\Delta L / L$ value. In the range of 45 to $85 \mathrm{GPa}$, the $\Delta L / L$ dependence on Young's modulus is well described by a power function, according to which the acceleration sensitivity $\Delta L / L$ is inversely proportional to the Young's modulus. Similarly, simulations were performed in order to estimate the influence of the Poisson ratio on the $\theta_{o}$ and $\Delta L / L$ values. During these simulations the resonator length was set to $L=50$ $\mathrm{mm}$, the Young's modulus E=67.6 GPa and the density $\rho=2210 \mathrm{~kg} / \mathrm{m}^{3}$. The simulation results are plotted in Fig. 5. The numeric calculations show that the acceleration 
sensitivity $\Delta L / L$ is independent of the Poisson ratio, but the squeeze insensitive angle $\theta_{o}$ can vary linearly in the range of a couple of degrees.

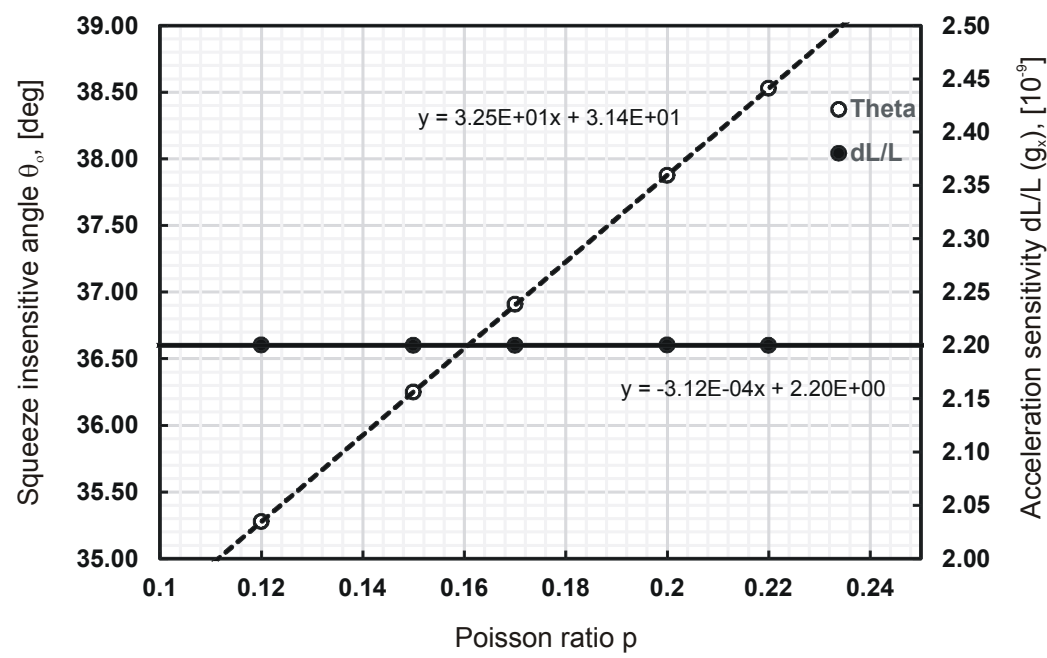

Fig. 5. The calculated squeeze insensitive angles $\theta_{o}$ and acceleration sensitivity $\Delta L / L$ at corresponding $\theta_{o}$ of $50 \mathrm{~mm}$ FP cavity as a function of the Poisson ratio. The Young's modulus and density were set to be $\mathrm{E}=67.6 \mathrm{GPa}$ and $\rho=2210 \mathrm{~kg} / \mathrm{m}^{3}$, respectively. The boundary conditions include a constant squeezing force $\mathrm{F}_{-\mathrm{z}}$ of $10 \mathrm{~N}$ as well as the gravitational body load.

We also estimated how the density of material $\rho$ determines the characteristics of the FP cavity. In Fig. 6, the calculated squeeze insensitive angle $\theta_{o}$ value and acceleration sensitivity $\Delta L / L$ of $50 \mathrm{~mm}$ resonator as a function of the density are displayed. During these simulations the Young's modulus and the Poisson ratio were set to $\mathrm{E}=67.6 \mathrm{GPa}$ and $p=0.17$, respectively. The squeeze insensitive angle $\theta_{o}$ value appears not to be influenced by the material density, while the acceleration sensitivity $\Delta L / L$ increases linearly as denser materials are employed (Fig. 6). The calculated acceleration sensitivity dependence on the material parameters can be used to estimate and to eventually compare $\Delta L / L$ for different materials. Assuming that linear mechanics can be used for the characterisation of the FP cavity deformations, $\Delta L / L$ can be interpolated and extrapolated from the approximation functions of $\Delta L / L$ shown in Figs. 4-6. For example, for a $50 \mathrm{~mm}$ cavity with parameters as those of ULE glass shown in Table 1 , the $\Delta L / L$ value is $2.21 \cdot 10^{-9}[1 / \mathrm{g}]$. On the assumption of linear mechanics approximation, the $\Delta L / L$ value for a cavity made of monocrystalline silicon material can be estimated using $\Delta L / L$ versus the material constant fits. For a $50 \mathrm{~mm}$ monocrystalline silicon cavity with the Young's modulus E=187 GPa and the density $\rho=2327 \mathrm{~kg} / \mathrm{m}^{3}$, we first use $\Delta L / L$ as a function of Young's modulus fit (see Fig. 4) and then $\Delta L / L$ as a function of the density fit (see Fig. 6). Such an approach yields the acceleration sensitivity $\Delta L / L$ of $0.92 \cdot 10^{-9}[1 / \mathrm{g}]$. This value is more than two times lower than $\Delta L / L$ of the cavity made of the ULE glass. Similarly, the acceleration sensitivity $\Delta L / L$ for cavities made of materials displayed in Table 2 was estimated and plotted in a bar graph (Fig. 7). From it, it is apparent that the cavity made of monocrystalline silicon would be the least sensitive to outer accelerating sensitivity compared to the other materials from the provided list. 


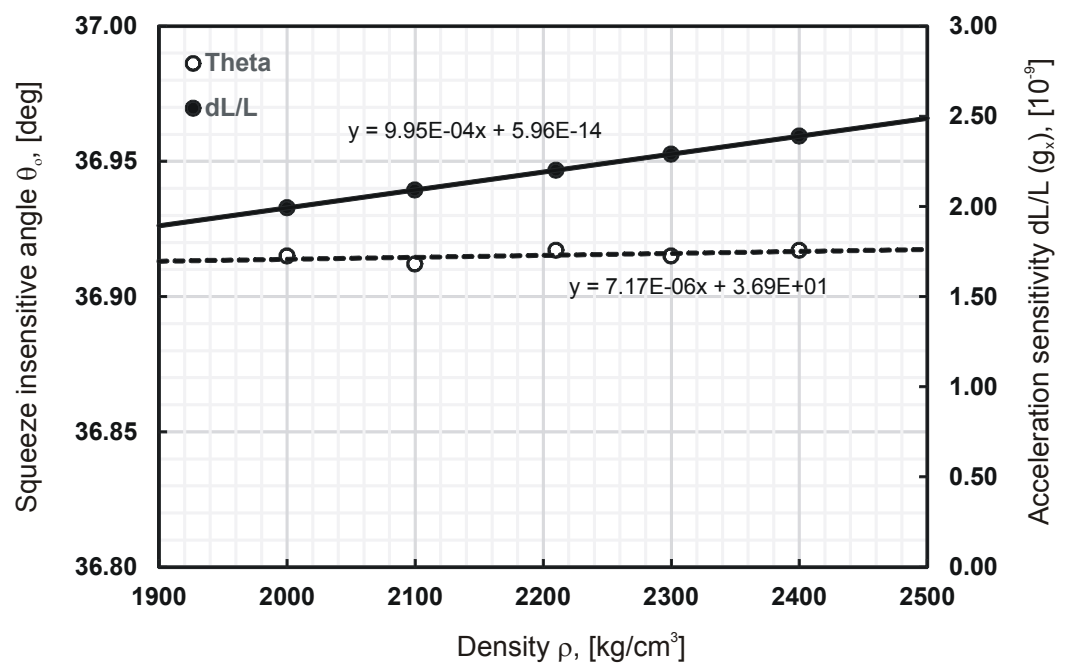

Fig. 6. The calculated squeeze insensitive angles $\theta_{o}$ and acceleration sensitivity $\Delta \mathrm{L} / \mathrm{L}$ at the corresponding $\theta_{o}$ of $50 \mathrm{~mm}$ FP cavity as a function of the material density. The Young's modulus and the Poisson ratio were set to $\mathrm{E}=67.6 \mathrm{GPa}$ and $p=0.17$, respectively. The boundary conditions include a constant squeezing force $\mathrm{F}_{-\mathrm{z}}$ of $10 \mathrm{~N}$ as well as the gravitational body load.

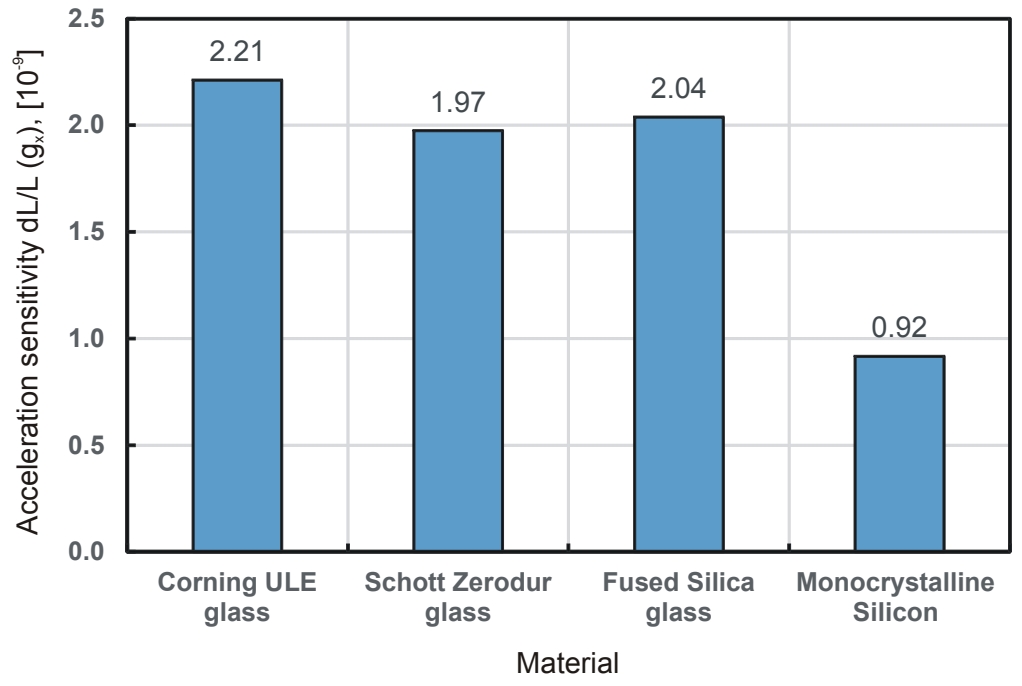

Fig. 7. The calculated acceleration sensitivity $\Delta L / L$ of $50 \mathrm{~mm}$ FP cavity made of materials listed in Table 2. The extrapolation of the numerical simulations suggests that from the provided material list the monocrystalline silicon cavity would be the least sensitive to outer accelerating sensitivity.

Clearly, we expected that the size of the cavity would play an important role in the cavity acceleration sensitivity $\Delta L / L$. In Fig. 8, the corresponding parameter has been calculated for cavities with sizes in the range from $50 \mathrm{~mm}$ to $150 \mathrm{~mm}$ and the material constants as those of the ULE glass shown in Table 2. Evidently, the acceleration sensitivity depends linearly on the cavity size - the bigger the cavity, the higher the acceleration sensitivity. 


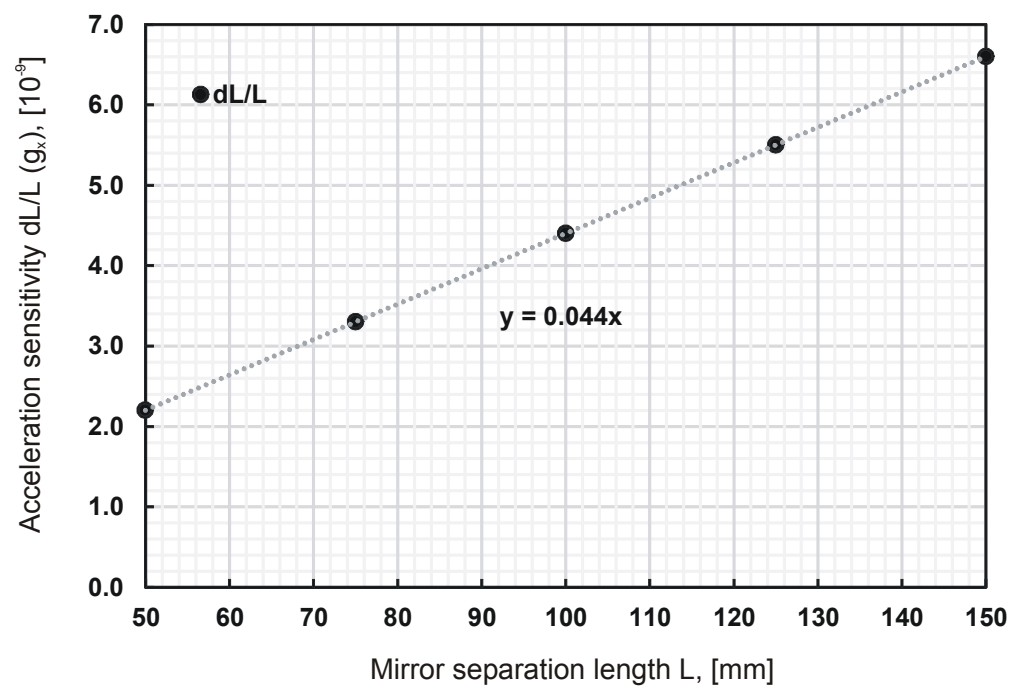

Fig. 8. The calculated acceleration sensitivity $\Delta L / L$ as a function of the cavity size $L$ in mm. The Young's modulus, the Poisson ratio and the density were set to $\mathrm{E}=67.6 \mathrm{GPa}, p=0.17$ and $\rho=2210 \mathrm{~kg} / \mathrm{m}^{3}$, respectively. The boundary conditions include a constant squeezing force $\mathrm{F}_{-\mathrm{z}}$ of $10 \mathrm{~N}$ as well as the gravitational body load.

Summarising the results of the static deformation simulations, the acceleration sensitivity $\Delta L / L$ is proportional to the length of the cavity and the density of the cavity material, but inversely proportional to the Young's modulus of the cavity material. Such a relation also governs the acceleration sensitivity for a vertically fixed cylindrical cavity, for which the mentioned parameter can be calculated analytically [9], [20].

\section{RESONANCE FREQUENCY STUDIES}

All previous calculations were time independent giving static deformations after applied force or load. These deformations could be considered deformations at frequency of $0 \mathrm{~Hz}$. The actual deformations taking place in the cavity are frequency dependent. If the cavity is deformed at its mechanical resonance frequency, the amplitude of induced deformations can be several orders higher than that of a static case. The resonance frequencies can be damped by means of appropriate fixing strength and cavity holder materials [7]. To stabilise the laser frequency, it is therefore suggested to select cavities with higher resonance frequencies, since those are usually easier to be damped [29]. Taking this into account, it is valuable to estimate the resonance frequency ranges for the cavities beforehand in order to make a well-grounded choice of the cavity material and dimensions. The cavity size has the greatest influence on the resonance frequency value. In Fig. 9, the calculated first five resonance modes for different cavities with sizes ranging from $50 \mathrm{~mm}$ to 150 $\mathrm{mm}$ are plotted. It is evident that the larger the spherical FP cavity, the lower its resonance frequency is. The relation between the cavity size and its resonance frequency is almost exponential suggesting that for the application in frequency stabilisation 
the smaller cavities should be favoured over the larger ones. The deformation of the spherical cavity when excited by the first five vibrational modes is shown graphically in Table 3.

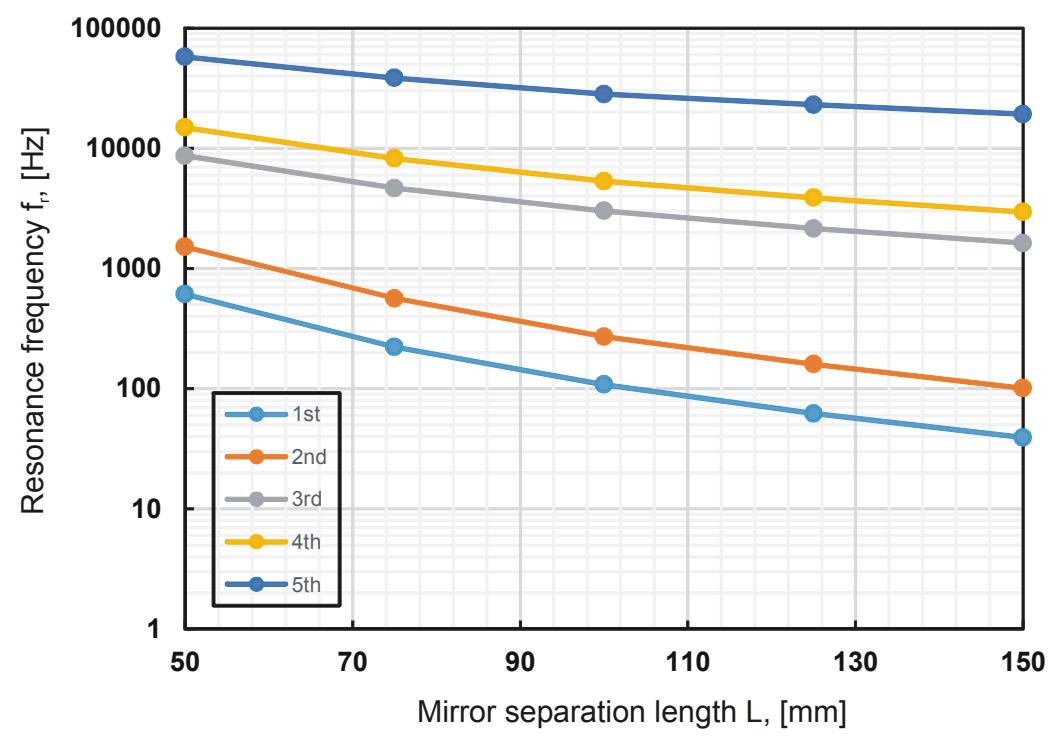

Fig. 9. The calculated resonance frequency dependence on the cavity size $\mathrm{L}$ in $\mathrm{mm}$. The first five resonance modes are displayed. The Young's modulus, the Poisson ratio and the density were set to $\mathrm{E}=67.6 \mathrm{GPa}, p=0.17$ and $\rho=2210 \mathrm{~kg} / \mathrm{m}^{3}$, respectively. In the plot, the vertical axis is logarithmic.

The First Five Vibrational Modes of a $50 \mathrm{~mm}$ FP Cavity with the Young's Modulus, the Poisson Ratio and the Density Set to $\mathbf{E}=67.6 \mathrm{GPa}, p=0.17$ and $\rho=2210 \mathrm{~kg} / \mathrm{m}^{3}$, Respectively.

\begin{tabular}{|c|c|c|c|c|}
\hline $1^{\text {st }}$ mode & $2^{\text {nd }}$ mode & $3^{\text {rd }}$ mode & $4^{\text {th }}$ mode & $5^{\text {th }}$ mode \\
\hline & & &
\end{tabular}

Note: The total displacement of the surface is plotted on the sphere, where blue indicates zero or low displacement and red - high displacement.

According to the numerical simulations, the variance material constants have much less influence on the resonance frequency shift for a spherical FP cavity. We estimated the shift of resonance frequencies after changing the material constants by a considerable amount. It was estimated that for a $50 \mathrm{~mm}$ FP cavity with material constants as those of the ULE glass, an increase in the Young's modulus by $10 \mathrm{GPa}$ shifted the resonance frequencies by $\sim+7 \%$, an increase in the Poisson ratio by 0.1 shifted the resonance frequencies only by $\sim-0.4 \%$, but an increase in the density by $100 \mathrm{~kg} / \mathrm{m}^{3}$ caused the resonance frequency shift of $\sim-2.4 \%$. 


\section{CONCLUSIONS}

The results of numerical studies of mechanical properties and deformations of the spherical FP cavity have outlined some important properties of an appropriate simulation model and the characteristics of the cavity sensitivity to environmental perturbations.

During the development of an appropriate spherical cavity simulation model, we created two designs: a full 3D model of the cavity and a simpler 2D simulation model employing the simulation on the symmetry plane of the cavity. This was done in order to understand whether the 3D simulations being much more timeconsuming could be substituted by much simpler 2D simulations. In both cases, the squeeze insensitive angle $\theta_{o}$ was calculated for cavities of different sizes. The results indicated that $2 \mathrm{D}$ simulations provided a squeeze insensitive angle $\theta_{o}$ that was by approximately $4.7^{\circ}$ higher than that obtained in the $3 \mathrm{D}$ simulation. This difference may arise from the fact that the mirror separation is also influenced by the out-ofsymmetry plane deformations of the cavity. Such a difference in the obtained results suggests that the 2D model that implements symmetry of the spherical cavity should not be used to predict the properties of a real spherical 3D FP cavity.

The main result of the simulations for static deformations of the cavity was that the acceleration sensitivity of the spherical FP cavity was proportional to the length of the cavity and the density of the cavity material, but inversely proportional to the Young's modulus. The deformations are independent of the Poisson ratio of the cavity material.

An important parameter of the FP cavity is its mechanical resonance frequency. If the cavity is deformed at its mechanical resonance frequency, the amplitude of induced deformations can be several orders higher than that of a static case. It is valuable to have a cavity possessing the mechanical frequencies as high as possible, since high frequencies are much easier to damp than the lower ones. According to numerical simulations, the material constants have much less influence on the resonance frequency shift for the spherical FP cavity. We have demonstrated that the mechanical resonance frequencies of the cavity are mainly determined by the size of the cavity: the smaller the cavity, the higher the expected mechanical resonance frequencies are. The relation between the size of the cavity and its mechanical resonance frequency is almost exponential.

\section{ACKNOWLEDGEMENTS}

The research has been supported by the European Regional Development Fund within the project "Competence Centre of Latvian Electronic and Optical Equipment Production", individual research project No. 1.4., programme "Entrepreneurship and Innovations" Appendix 2.1.2.1.1. activity "Centres of Competence", contract No. L-KC-11-0006. 


\section{REFERENCES}

1. Willke, B., Danzmann, K., Frede, M., King, P., Kracht, D., Kwee, P., Puncken, O., Savage, R. L., Schulz, B., Seifert, F., Veltkamp, C., Wagner, S., Weßels, P. and Winkelmann, L. (2008). Stabilized lasers for advanced gravitational wave detectors. Class. Quantum Gravity 25, 114040.

2. Pellegrini, S., Buller, G.S., Smith, J.M., Wallace, A.M., and Cova, S. (2000). Laser-based distance measurement using picosecond resolution time-correlated single-photon counting. Meas. Sci. Technol. 11, 712-716.

3. Eisele, C., Nevsky, A., and Schiller, S. (2009). Laboratory test of the isotropy of light propagation at the 10-17 level. Phys. Rev. Lett. 103, 090401.

4. Gill, P. (2005). Optical frequency standards. Metrologia 42, S125-S137.

5. Rafac, R., Young, B., Beall, J., Itano, W., Wineland, D., and Bergquist, J. (2000). Subdekahertz ultraviolet spectroscopy of $199 \mathrm{Hg}+$. Phys. Rev. Lett. 85, 2462-2465.

6. Thorpe, M.J., Rippe, L., Fortier, T.M., Kirchner, M.S., and Rosenband, T. (2011). Frequency stabilization to $6 \times 10-16$ via spectral-hole burning. Nat. Photonics 5, 688-693.

7. Alnis, J., Matveev, A., Kolachevsky, N., Udem, T., and Hänsch, T.W. (2008). Subhertz linewidth diode lasers by stabilization to vibrationally and thermally compensated ultralow-expansion glass Fabry-Pérot cavities. Phys. Rev. A 77, 053809.

8. Drever, R.W.P., Hall, J.L., Kowalski, F.V., Hough, J., Ford, G.M., Munley, A.J., and Ward, H. (1983). Laser phase and frequency stabilization using an optical resonator. Appl. Phys. B Photophysics Laser Chem. 31, 97-105.

9. Notcutt, M., Ma, L.S., Ye, J., and Hall, J.L. (2005). Simple and compact 1-Hz laser system via an improved mounting configuration of a reference cavity. Opt. Lett. 30, $1815-1817$.

10. Webster, S., Oxborrow, M., and Gill, P. (2007). Vibration insensitive optical cavity. Phys. Rev. A 75, 011801.

11. Alnis, J., Matveev, A., Kolachevsky, N., Wilken, T., Holzwarth, R., and Hänsch, T.W. (2008). Stable diode lasers for hydrogen precision spectroscopy. Eur. Phys. J. Spec. Top. 163, 89-94.

12. Millo, J., Magalhães, D., Mandache, C., Le Coq, Y., English, E., Westergaard, P., Lodewyck, J., Bize, S., Lemonde, P., and Santarelli, G. (2009). Ultrastable lasers based on vibration insensitive cavities. Phys. Rev. A 79, 053829.

13. Jin, M., Yan-Yi, J., Su, F., Zhi-Yi, B., and Long-Sheng, M. (2009) Vibration insensitive optical ring cavity. Chinese Phys. B 18, 2334-2339.

14. Leibrandt, D.R., Thorpe, M.J., Notcutt, M., Drullinger, R.E., Rosenband, T., and Bergquist, J.C. (2011). Spherical reference cavities for frequency stabilization of lasers in non-laboratory environments. Opt. Express 19, 3471-82.

15. Webster, S., and Gill, P. (2011). Force-insensitive optical cavity. Opt. Lett. 36, 3572-4.

16. Alnis, J., Schliesser, A., Wang, C.Y., Hofer, J., Kippenberg, T.J., and Hänsch, T.W. (2011). Thermal-noise-limited crystalline whispering-gallery-mode resonator for laser stabilization. Phys. Rev. A 84, 011804.

17. Numata, K., Kemery, A., and Camp, J. (2004). Thermal-noise limit in the frequency stabilization of lasers with rigid cavities. Phys. Rev. Lett. 93, 250602.

18. Leibrandt, D.R., Thorpe, M.J., Bergquist, J.C., and Rosenband, T. (2011). Field-test of a robust, portable, frequency-stable laser. Opt. Express 19, 10278-10286.

19. Vogt, S., Lisdat, C., Legero ,T., Sterr, U., Ernsting, I., Nevsky, A., and Schiller, S. (2011). Demonstration of a transportable $1 \mathrm{~Hz}-$ linewidth laser. Appl. Phys. B 104, 741-745. 
20. Chen, L., Hall, J., Ye, J., Yang, T., Zang, E., and Li, T. (2006). Vibration-induced elastic deformation of Fabry-Perot cavities. Phys. Rev. A 74, 053801.

21. Nazarova, T., Riehle, F., and Sterr, U. (2006).Vibration-insensitive reference cavity for an ultra-narrow-linewidth laser. Appl. Phys. B 83, 531-536.

22. Hall, J., Taubman, M., and Ye, J. (2001). Laser stabilization. In Handbook of Optics, M. Bass, ed., 2nd ed. McGRAW-HILL, p. 814.

23. Davis, M.J., Hayden, J.S., and Farber, D.L. (2007). High-precision thermal expansion measurements using small Fabry-Perot etalons. In Proceedings of SPIE - The International Society for Optical Engineering, R. J. Jones, ed. , Vol. 6673, p. 66730R66730R-12.

24. Numata, K., Bianc, G.B., Ohishi, N., Sekiya, A., Otsuka, S., Kawabe, K., Ando, M., and Tsubono, K. (2000). Measurement of the intrinsic mechanical loss of low-loss samples using a nodal support. Phys. Lett. A 276, 37-46.

25. Richard, J.-P., and Hamilton, J.J. (1991). Cryogenic monocrystalline silicon Fabry-Perot cavity for the stabilization of laser frequency. Rev. Sci. Instrum. 62, 2375.

26. Kessler, T., Hagemann, C., Grebing, C., Legero, T., Sterr, U., Riehle, F., Martin, M.J., Chen, L., and Ye, J. (2012). A sub-40-mHz-linewidth laser based on a silicon singlecrystal optical cavity. Nat. Photonics 6, 687-692.

27. Tao, R., Hinchet, R., Ardila, G., and Mouis, M. (2013). Evaluation of vertical integrated nanogenerator performances in flexion. J. Phys. Conf. Ser. 476, 012006.

28. Liang, Z., and Hua-Min, Q. (2014). Mechanical research and development of monocrystalline silicon neutron beam window for CSNS. Chinese Physics $C, 5$.

29. Nevsky, A.Y., Eichenseer, M., von Zanthier, J., and Walther, H. (2002). A Nd:YAG Laser with short-term frequency stability at the Hertz-level. Opt. Commun. 210, 91-100.

\title{
SKAITLISKU 2D UN 3D APRĒKIINI SFĒRISKAM FABRI-PERO REZONATORAM ĀRĒJĀS LĀZERA FREKVENCES STABILIZĒŠANAI
}

\author{
E. Nitišs, K. Blušs, J. Alnis
}

\section{Kopsavilkums}

Šajā darbā mēs demonstrējam rezultātus, kas iegūti veicot skaitliskus deformāciju aprēķinus Fabri-Pero rezonatoram, ko varētu lietot kā ārējo referenci lāzera frekvences stabilizēšanai. Tiek demonstrēts, ka, lai precīzi spētu novērtēt lodes Fabri-Pero rezonatora deformācijas ārējas mehāniskas iedarbības rezultātā, nepieciešams $2 \mathrm{D}$ simulācijas vietā veikt aprēķinus $3 \mathrm{D}$ telpā. Neskatoties uz to, ka 2D skaitliskajos aprēķinos tiek ņemta vērā problēmas simetrija, tie nespēj sniegt precīzu deformāciju amplitūdu novērtējumu. Vēl tiek skaidroti optimālie parametri lodes Fabri-Pero rezonatora stiprināšanai un materiālu izvēlei tā, lai tā formu pēc iespējas maz ietekmētu ārējā mehāniskā iedarbība. Tiek parādīts, ka vismazākā jutība pret ārējiem mehāniskiem trokšṇiem tiek iegūta, kad lodes rezonatora izgatavošanai izmanto materiālu ar pēc iespējas mazu blīvumu un augstu Junga moduli. Tiek arī demonstrēta mehānisko rezonanšu atkarība no lodes Fabri-Pero rezonatora izmēra.

08.04.2015. 